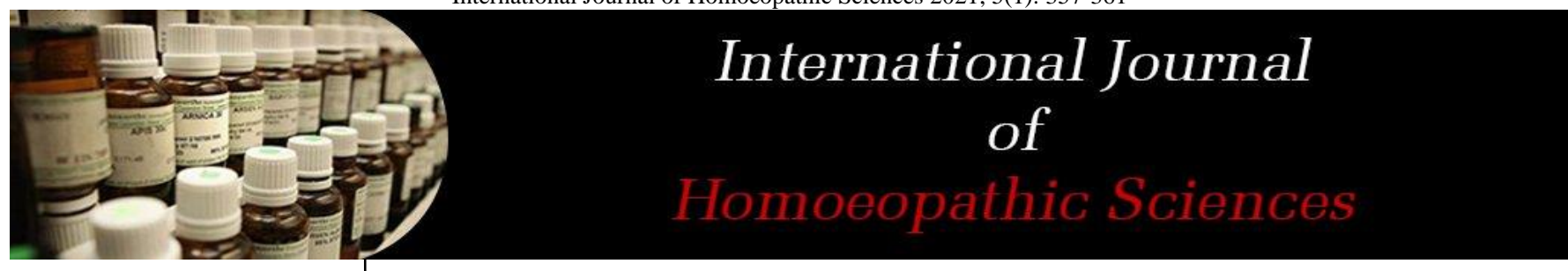

E-ISSN: 2616-4493 P-ISSN: 2616-4485 www.homoeopathicjournal.com IJHS 2021; 5(1): 357-361 Received: 22-11-2020 Accepted: 24-12-2020

\section{Dr. Kanak Kumar}

Head of Department of Practice of Medicine, R.B.T.S., Govt. Homoeopathic Medical College and Hospital, Muzaffarpur, Bihar, India
Corresponding Author: Dr. Kanak Kumar Head of Department of Practice of Medicine, R.B.T.S., Govt. Homoeopathic Medical College and Hospital, Muzaffarpur, Bihar, India

\title{
Ulcerative lesions a primary aspect
}

\section{Dr. Kanak Kumar}

\section{DOI: https://doi.org/10.33545/26164485.2021.v5.i1f.339}

\section{Abstract}

Lesions of the skin or of a mucous membrane which is accompanied by formation of pus and necrosis of surrounding tissue, usually resulting from inflammation or ischemia. A break in skin or mucous membrane with loss of surface tissue, disintegration and necrosis of epithelial tissue and often pus. Ulceration occurs as a result of dermal or subcutaneous tissue loss, and it usually develops on the base of a tumoral or inflammatory nodule. Thus, an important part of the diseases in this chapter were also mentioned in other chapters of the book. Ulcerative lesions may sometimes develop due to trauma.

Keywords: basal cell carcinoma, cutaneous leishmaniasis, mycosis fungoides, pyoderma gangrenosum

\section{Introduction}

Nearly everyone suffers from mouth ulcers at one time or the other in their lives. Most would also agree that these insignificant-looking ulcers can cause major discomfort ${ }^{[1]}$. For some people, the irritation and pain can be so troublesome that it tends to disrupt their daily life ${ }^{[2]}$. Homeopathic medicines for mouth ulcers work well to treat the ulcers quickly, and also to help prevent their recurrence. Natural medicine for mouth ulcers treatment also helps during the acute phase of the condition in reducing the pain as well as the duration of ulcers ${ }^{[3,4]}$. Mouth ulcers are more common in women than in men ${ }^{[5]}$.

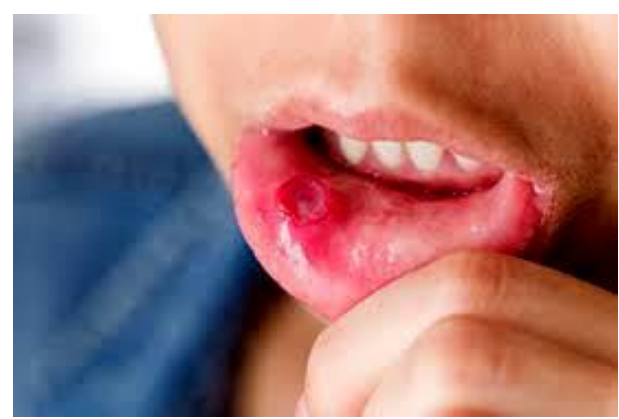

Fig 1: Showing ulcerative lesion

Pain caused by these ulcers can at times be so severe that it can limit the ability to speak and eat properly. Besides the pain, mouth ulcers have another troublesome feature associated with them- 'frequent recurrence.' These ulcers tend to occur very frequently in some people [6]. It is a common issue with mouth ulcers that while the first lot is not fully healed, new ulcers are already on their way. Mouth ulcers (apthae) also tend to occur in crops or multiple numbers ${ }^{[7,8]}$.

Allopathic treatment for recurrent mouth ulcers involves pain management and lowering the healing time of the ulcer ${ }^{[9]}$. However, conventional treatment does not cure the ulcers permanently. The usual advice involves using a rinse of saltwater, antiseptic liquids, baking soda or steroid to reduce the pain, but the underlying cause remains the same. This increases the tendency to develop ulcers again and again. Biochemic medicine for mouth ulcer works by naturally treating the cause of the problem ${ }^{[10,11]}$. Merc Sol for mouth ulcers and borax for mouth ulcers are some common medicines. Homeopathy medicines help heal mouth ulcers quickly without any side effects ${ }^{[12]}$.

Mouth ulcers usually need time to heal ${ }^{[3]}$. There is no quick fix to this condition, but homeopathy medicines can help speed up the healing process and also reduce the pain. Recurrence of mouth ulcers is also minimized through the use of homeopathy remedies ${ }^{[9]}$ 

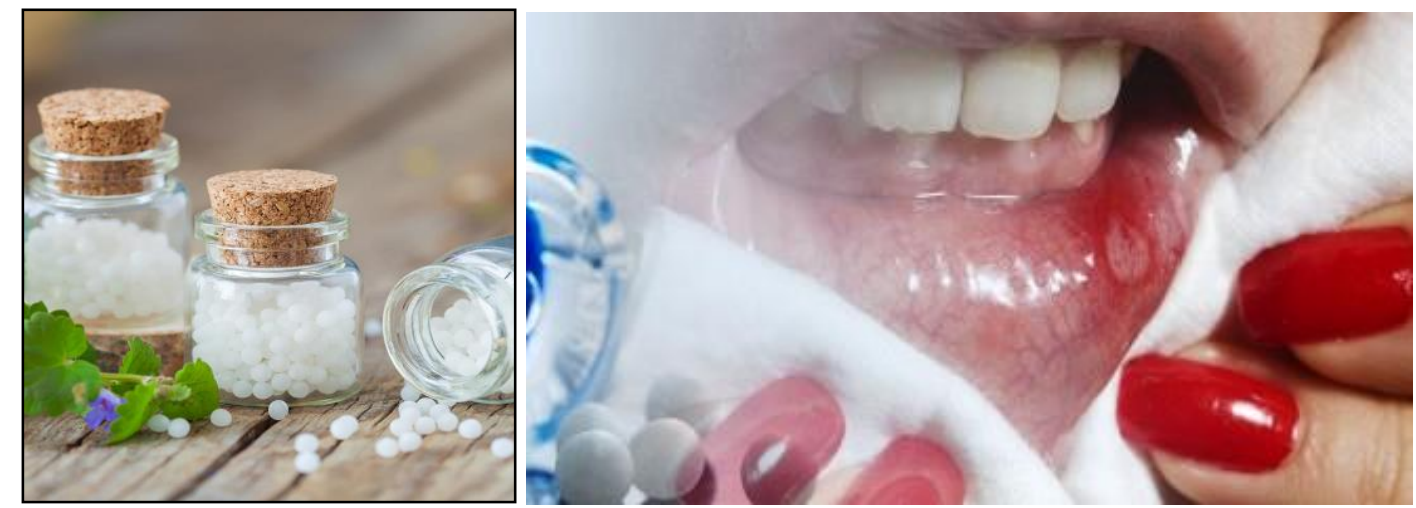

Fig 2: Showing Homoeopathic remedies for ulcerative lesion

\section{Mercurius Solubilis}

Mercurius Solubilis is a medicine for mouth ulcers derived from the trituration of quicksilver. It shows a powerful action on every organ and tissue of the body. Merc Sol not only hastens the healing of ulcers and reduces the pain, but it also eradicates the tendency of frequent mouth ulcers. It is (for most of the homeopathic physicians) the first line of treatment for mouth ulcers. It is indicated for all kind of ulcers whether small or big and in severe cases where the mouth is inflamed with burning aphthous ulcers with salivation with a lot of salivation. It is also helpful in certain other aphthous conditions: pale mucous membrane( mouth lining) with numerous erosions, small, flat ulcers with red, inflamed edges on the tongue and inside of lips and cheeks. Excessive saliva in the mouth and desire for cold water while having ulcers are indications for this medicine. A foul, metallic taste of the saliva, confluent oral thrush that changes into ulcers, and diffused redness of the whole mucous membrane of the mouth with profuse salivation.

\section{Borax Veneta}

Borax is a medicine derived from sodium bicarbonate. Sodium bicarbonate was used in the earlier times to neutralize the effect of excessive acids produced by the stomach. In homeopathy, it is used to treat ulcers that have a tendency to bleed easily when touched, or during eating. Other key indications for borax to be used are dryness in the mouth with rapid formation of the ulcers. The ulcers appear in the mouth and on the inner surface of the cheeks. It is also used for mouth ulcers in infants and babies.

\section{Nitricum Acidum}

Nitricum acidum is a medicine derived from the trituration of the nitric acid. It has a marked action on the outlets of the body where the mucous membranes meet the skin. It is used to treat ulcers that appear on the soft palate, within the cheeks and on the edges of the tongue. It is mostly used when the whole mouth is ulcerated and the pain are severe. For medicine Nitric acid to be used the key indications are sticking pains in ulcers like that from a splinter. It is also used in cases where the mucous membrane gets easily bitten, swollen and ulcerated. The Swollen mucous membrane, such as ulcerated tender gums, do not allow the patient to chew food.

\section{Muratic Acidum}

Muratic Acidum is a medicine used to treat mouth ulcers where the mouth is studded with ulcers that tend to perforate. The ulcers usually have a dark or black base, and there is excessive redness inside the cheeks and the palate.
Usually, the red, inflamed and painful ulcers occur as a result of aphthous stomatitis. There may be a lot of dryness of the mouth.

\section{Kalium Iodium}

Kalium Iodum is a medicine for mouth ulcers that is used in cases where irregular ulcers appear in the mucous membrane of the mouth. They look as if they have a milky coating. Along with ulcerative condition of the mouth, copious salivation, offensive mouth odor, heat in the mouth, swelling, dryness, and bitterness in the mouth are, and pharynx are some symptoms that indicate the need for this medicine.

\section{Natrum Muriaticum}

Natrum Mur. is a medicine for mouth ulcers that develop with oral thrush. There is dryness of the mouth, lips an tongue, soreness of the mouth with sensitivity to liquids, burning pain when food or liquids touch the ulcer, small grouped ulcers on the tongue, gums, and cheeks with burning along with profuse watery saliva from the mouth.

\section{Discussion}

\section{So what exactly are mouth ulcers?}

Mouth ulcers (also known as aphthous ulcers or canker sores) are shallow, painful sores inside the mouth. They appear as painful white or yellow ulcers surrounded by a bright red area. A mouth ulcer is a lesion in the mucous membrane ${ }^{[3]}$. The development of an ulcer begins with a burning sensation followed by a red spot which then progresses into an ulcer. They can make eating, drinking, and talking uncomfortable ${ }^{[4]}$.

\section{Are mouth ulcers contagious?}

No, these are non-contagious and benign in nature and do not pose any risk.

The pain from an ulcer usually subsides over a week, and the final healing takes place within 2-3 days. There may be mild to moderate fever accompanying the ulcer.

Mouth ulcers are different from another condition called fever blisters, which usually occur on the lips and corners of the mouth ${ }^{[2]}$.

The most common sites places where mouth ulcers appear are:

- Inside of the lips

- Inside of the cheeks

- Base of gums

- Under the tongue

- On the palate

Ulcers on the tongue are also fairly common. 


\section{What are the causes of Recurrent Mouth Ulcers?}

- The exact cause and process of development of mouth ulcers is not known ${ }^{[7]}$. Ulcers can be the result of a combination of conditions, like:

- A mechanical injury caused by the sharp edges of teeth, fillings, crowns, dentures, braces or even accidental biting of the inner mouth can lead to an ulcer due to irritation. Eating rough foods or putting sharp things like pens, toothpicks or fingernails in the mouth can also cause a tear in the mucous membrane, from where an ulcer can develop ${ }^{[5]}$.

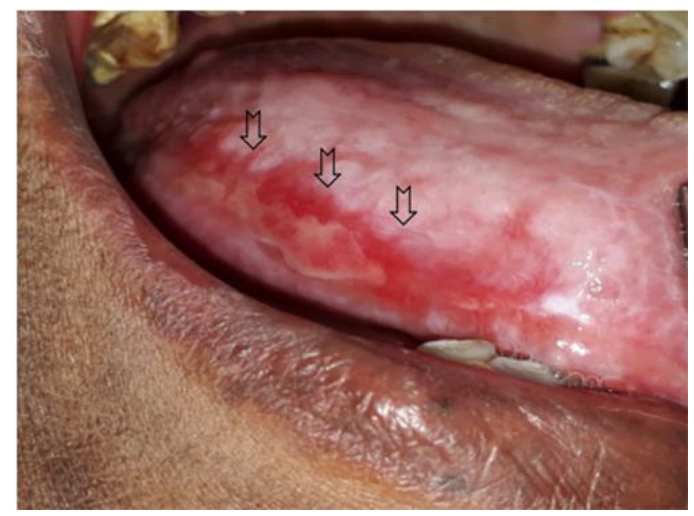

Fig 3: Showing ulcerative lesion due to mechanical injury

- Putting hot food or beverages in the mouth can cause redness inside the mouth, especially in sensitive areas like the palate or the lining of the cheeks and back of the lips and lead to an ulcer ${ }^{[4]}$.

- Any strong or concentrated caustic chemicals, when kept for long in the mouth, can cause a chemical trauma inside the mouth. For example, holding medicine in the mouth instead of swallowing it can create a problem if the medicine is strong. Such injuries are more common in children or people under psychiatric care ${ }^{[9]}$.

- A viral, bacterial, fungal, parasitic contact can contribute to the growth of infection inside the mouth. A weakened immune system and a tear in the mucous membrane of the mouth can lead to the development of ulcers on the inner lining of the mouth.

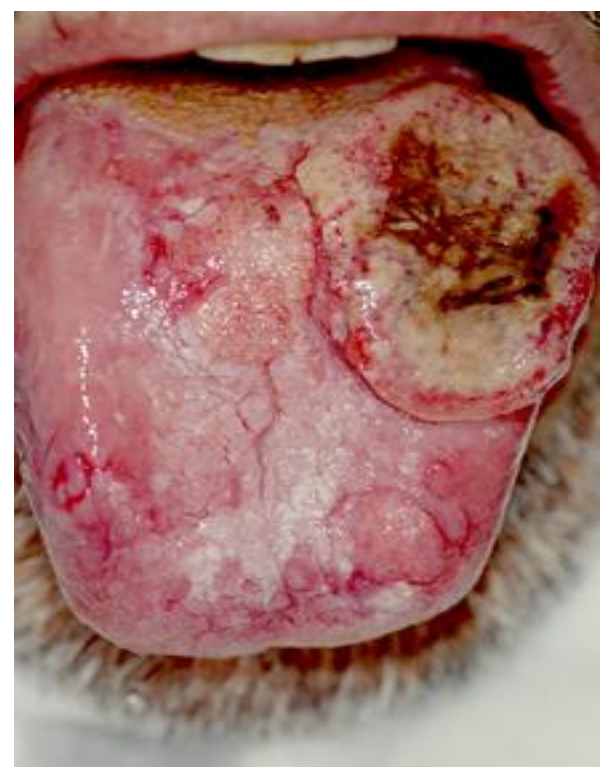

Fig 4: Showing ulcerative lesion due to fungal and parasitic colony formation
- Mouth ulcers can occur as a side effect of medications like antibiotics, painkillers, steroids, analgesics, NSAID's (Non-Steroidal Anti-inflammatory Drugs) ${ }^{[7]}$.

- Deficiency of Vitamin B12 and iron can trigger the growth of ulcers.

- Tobacco is a major cause of mouth ulcers, so smoker's are more prone to develop recurrent mouth ulcers. Alcohol also triggers mouth ulcers by disrupting the absorption of nutrients in the system ${ }^{[3]}$.

- Recurrent Aphthous Stomatitis (Canker Sore) is the most common cause of the recurrent mouth ulcers. This condition causes the recurrent formation of oral ulcers for reasons unknown ${ }^{[11]}$.

- Xerostomia is a sensation of dry mouth that is often associated with the decreased functionality of salivary glands. This prevents lubrication of the mucous membranes and due to excessive dryness in the mouth, lesions can appear inside the mouth ${ }^{[9]}$.

- The herpes simplex virus (HSV-1) also causes mouth ulcers as a symptom of the herpes infection ${ }^{[7]}$.

Other factors that can contribute to the occurrence of recurrent mouth ulcers are:

- Poor oral hygiene

- Diabetes

- Emotional stress

- Dermatological causes like lichen planus, lupus erythematosus.

- Products containing SLS (sodium lauryl sulfate), like toothpaste and mouthwash.

- Gastrointestinal causes like celiac disease, Crohn's disease, ulcerative colitis, etc.

- Epithelial atrophy that makes the lining more fragile and easily breached.

- Radiation-induced stomatitis is more common after radiotherapy. It can cause mucosal erosions and ulcerations on the lower jaw.

- Vesiculobullous Diseases lead to the development of vesicles and bullae formation on the mucous membranes of the oral cavity, which tend to be fragile and quickly break down. These leave behind ulcers in the mouth.

\section{What factors lead to Mouth Ulcers?}

Mouth ulcers can also be triggered by certain other factors Family tendency: Someone who has a family tendency of having recurrent mouth ulcers can be at high risk of developing it.

Hormonal changes: Due to hormonal changes that usually occur during menstruation, pregnancy or menopause, some women tend to experience oral changes that include the development of canker sores or bleeding from the gums.

Medications like NSAID's (nonsteroidal anti-inflammatory drugs) and beta blockers tend to increase a person's tendency to develop canker sores.

Chronic conditions like inflammatory bowel disease or celiac disease are usually autoimmune disorders that can manifest themselves orally (in the form of ulcers) due to a weak immune response. 


\section{Signs and Symptoms of Mouth Ulcers}

Mouth ulcers feel like elevated areas inside the mouth, on areas like the inner cheeks, inside of the lips, under or on the tongue, and the sides of the tongue ${ }^{[11]}$.

Some common signs of a mouth ulcer include:

- yellow discoloration of the elevated area with the surrounding reddened edges. These can sometimes be coated with a white or milky lining.

- swelling inside the cheeks or the lips

- bleeding from the ulcers

- dryness in the mouth

- offensive odor from the mouth

Some common symptoms of recurrent mouth ulcers include

- Pain: Pain can range from mild to moderate or even severe and it depends completely on the individual case

- Discomfort: These can cause significant discomfort in eating, drinking or even while talking

- Tenderness of the affected area

- Burning sensation in the mouth

- Tingling in the affected area

- Warmth and dryness of the mouth with increased thirst

- Excessive salivation

- Irritation of the sores by acidic, rough or dry foods.

\section{Types of Mouth Ulcers}

Mouth ulcers are classified as ${ }^{[11]}$

Minor Ulcers: These are the most common type of the ulcers and are generally very small, oval or round. They appear in groups of 1-6 small ulcers. These tend to heal within one to two weeks and do not leave any permanent scars.

Major Ulcers: These are less common and larger and deeper as compared to minor ulcers. These come as deep lesions with irregular edges and can take up to six weeks to heal. These ulcers can result in long-term or permanent scarring and tend to become recurrent.

Major cankers can affect areas like the inside of the cheeks, lips, sides or under the surface of the tongue and the floor of the mouth.

Herpetiform: These ulcers are the least common type of ulcers. Herpetiform canker sores are small ulcers that usually appear in crops of about 10-100 ulcers. Adults tend to be more affected by these. The ulcers have irregular edges and are extremely painful. They tend to cause scarring as they heal, which can make it a recurrent problem.

\section{Diagnosing Mouth Ulcers}

Visual examination done by a physician can help diagnose mouth ulcers. If required, clinical investigations can be done to rule out the underlying cause, followed by appropriate treatment. In case the ulcers do not heal or reappear at short intervals, they tend to progress towards a more malignant condition. The main difference between mouth ulcers and cancer is the amount of time they take to heal, the number of sores and the pain associated.

\section{Tips to Prevent Mouth Ulcers}

Certain precautions can help minimize the risk of developing a mouth ulcer, like:

- Avoid foods that irritate the oral mucosa like acidic foods, nuts, spices.

- Avoid talking and eating at the same time to prevent local trauma caused by biting the inner cheeks or the lips.

- Maintain good oral hygiene by regularly flossing and brushing the teeth to prevent any infections in the mouth that can cause ulceration.

- Eat a balanced diet, high in nutrients and vitamins to avoid the occurrence of ulcers from nutritional deficiencies.

- Avoid stress as it may cause an altered immune response, leading to the occurrence of more ulcers.

- Avoid mouthwashes that contain sodium lauryl sulphate as they usually trigger mouth ulcers.

\section{Managing Mouth Ulcers}

- Use toothbrushes with soft bristles to avoid scraping the ulcers.

- Have cool drinks to soothe the ulcers.

- Eat soft foods.

- Get regular dental checkups to avoid the further damage caused by sharp teeth, braces or dentures.

\section{Conclusion}

Recurrent mouth ulcers are restricted to oral cavity only. Starts in childhood or adolescences as recurrent small rounds or ovoid ulcers with uncircumcised margins. Occurs on mucous membranes of the oral cavity. Ulcers are associated with many diseases so there is no serious underlying cause. Mouth ulcers often cause pain and discomfort and may alter person choice of food while healing occurs. Treatment strategies must be directed toward providing symptomatic relief by reducing pain, increasing the duration of ulcer-free periods, and accelerating ulcer healing. The effectiveness of treatment, however, is not clinically significant since pain relief and healing time is accelerated by only 1.3 and 1.6 days respectively and since a vehicle also reduces pain. The effectiveness of prevention showed statistically significant results; however, diagnosis of the prodromal stage is subjective, while the objective thermographic imaging is impractical and thus not clinically utilizable. The etiopathogenesis of this disease is yet unclear.

\section{References}

1. Allen CM, Camisa C, Salewski C, et al. Wegener's granulomatosis: report of three cases with oral lesions. J Oral Maxillofac Surg 1991;49(3):294-8.

2. Fauci AS. The vasculitis syndromes. In: Isselbacher KJ, Braunwald E, Wilson JD, et al, eds. Harrison's principles of internal medicine. 14th ed. New York: McGraw-Hill, 1998, 1910-22.

3. Frances C, Du LT, Piette JC et al. Wegener's granulomatosis: dermatological manifestations in 75 cases with clinicopathologic correlation. Arch Dermatol 1994;130(7):861-7.

4. Glass EG, Lawton LR, Truelove EL. Oral presentation of Wegener granulomatosis. J Am Dent Assoc 1990;120(5):523-5

5. Mishriki YY. The saga of the sore on the shin. Postgrad Med. Adi BS. Efficacy of homoeopathic medicines in chronic low back pain: a clinical study. International Journal of Alternative and Complementary Medicine. 2020, 17-20. 1998;103(5):109-11 [Taylor \& Francis 
Online]

6. Cohen PS, Meitzer JA. Strawberry gums: a sign of Wegener's granulomatosis. JAMA 1981;246(22):26101

7. Borins M. Traditional Medicine of India. Can Fam Physician 1987;33:1063-1065.

8. Caldis KS, McLeod HD, Smith PR. The Fall of The Bamboo Curtain: A Review of Complementary Medicine In South Africa. South African Actuarial Journal 2001;1:63-93.

9. Haila S, Koskinen A, Tenovuo J. Effects of homeopathic treatment on salivary flow rate and subjective symptoms in patients with oral dryness: a randomized trial. Homeopathy 2005;94(3):175-81.

10. Robinson T. Responses to homeopathic treatment in National Health Service general practice. Homeopathy 2006;95(1):9-14.

11. Bookman R. Relief of Canker Sores on Resumption of Cigarette Smoking. Calif Med 1960;93:235-6.

12. Natah SS, Konttinen YT, Enattah NS, Ashammakhi N, Sharkey KA, Häyrinen-Immonen R. Recurrent aphthous ulcers today: A review of growing knowledge. Int J Oral Maxillofac Surg 2004;33:221-34. 